\title{
Analyze Performance of Enterprise Supervision System by Game Theory-Take the case of Tatung Management Rights Competition as Example
}

\author{
Yu-Chun Huang* \\ Department of Business Administration, Shu-te University, Kaohsiung, 82445, Taiwan
}

\begin{tabular}{l} 
A R T I C L E I N F O \\
\hline Article history: \\
Received: 07 December, 2020 \\
Accepted: 08 March, 2021 \\
Online: 20 March, 2021 \\
\hline Keywords: \\
Enterprise Management \\
Enterprise Supervision \\
Game Theory \\
Fuzzy Set \\
Optimization \\
\hline
\end{tabular}

\begin{abstract}
A B S T R A C T
Protecting the rights and interests of shareholders is the important research topic. This study takes "Tatung Operation Rights Competition" as an example to execute case study. Game tools are applied to analyze which corporate supervision strategies should be used by government. The research and analysis results show that both the corporate group and the market group are suitable for using mixed strategies to compete for management rights in the operation rights competition case. However, doing something is the best regulatory strategy for government regulators to protect shareholders. In addition, this study suggests that government should assist enterprise with long-term business failures in their industrial upgrading and transformation in peacetime.
\end{abstract}

\section{Introduction}

In today's world, investment is very important issue especially in Taiwan because Taiwan citizen's per capita GDP has been reached US\$25,000 and Taiwan's nominal national savings rate is closed to $40 \%$ [1-2]. The volume of investor has been increasing in recent year (Refer to Figure 1). Among them, many Taiwanese citizens invest their funds in high-risk stock markets. The government should ensure that Taiwan investors are not cheated by major shareholders [3]. In order to ensure that Taiwan's stock market is fair, government should prevent insider trading. Therefore, Taiwan government is strengthening enterprise supervision for preventing companies to use various tools to harm shareholders in order to get benefit for themselves.

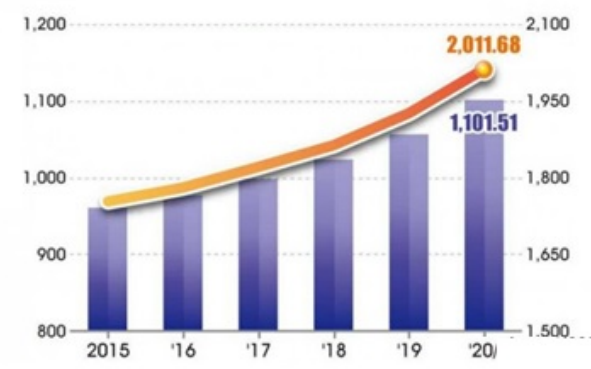

Figure 1: Account opening status of Taiwan stocks in the past 6 years

Yu-Chun Huang, yutsun314@stu.edu.tw
Due to limited government resources, it is impossible for government to inspect each company one by one in the face of all listed companies. This will cause market inefficiency and consume too much resources to visit companies with good credit. Therefore, Taiwan government mostly inspects and supervises a few companies that may have problems. The purpose of this research is to use game theory tool to analyze and evaluate the effectiveness of corporate supervision system and to provide some reasonable suggestions to government and enterprises.

This study is divided into five parts. In the beginning, research background, research motivation will be discussed. And then, the related literatures about enterprise supervision and game theory will be collected and arranged. Game evaluation model will be construct in next section. A case will be described and game analysis will be executed. Conclusion of this work and suggestions to the government and enterprises will be taken over as ending.

\section{Literature Review}

\subsection{Enterprise Supervision Research}

In [4], author explored the importance of the information transparency system based on the Asian financial crisis and used it to improve Taiwan's corporate supervision system. In [5], author designed questionnaires to investigate the issues of company supervision such as the company's board of directors and supervisory system. The research results show that the government should provide appropriate incentives to increase the importance 
of corporate directors and supervisors for executing corporate supervision. Shareholders should strengthen their concern for corporate supervision. The participation and the number of supervisors should be based on the scale of the company. In [6], author analyzed the lack of supervision mechanism of Taiwan enterprises based on the procomp informatics example and seek improvement direction. In [7], author analyzes the lack of corporate governance and financial supervision in the Liba case and compares it with past malpractice cases to sort out improvement measures.

In [8], author designed dynamic game models to evaluate the supervision performance of government supervision mechanism. Research result shows that the supervision mechanism was not feasible if enterprises may neglect product quality for short-term interests. This research suggests that punishment degree to violating enterprise should be increased and the regulation of secure food enterprises must be enhanced. In [9], author built supervision game model between manufacturing enterprises and government department in order to execute enterprise quality management. In this model, the mixed strategy for enterprises and government were decided based on Nash equilibrium mechanism . In [10], author thought that learning theory and information processing theory can be applied to enhance the supervision degree of enterprise. In [11], author designed the supervision game model between the online shopping platform and the governmental quality supervision department based on complete information. Research result shows that costs of governmental supervision will influence supervision effectiveness of government. In [12], author analyzed and discussed the enterprise supervision system based on the government's policies. Enterprise supervision system were used to effectively enhance the competitiveness of enterprises. In [13], author used evolutionary game to regulation mode for analyzing long-term evolutionary trend between dairy enterprise and government supervision. They applied Python matplotlib to simulate research results. Research results shows that the standard recall system of defect and dairy products can reduce government supervision cost.

\subsection{Information Asymmetry Theory}

Information Asymmetry refers to the fact that transaction information possesses by seller or buyer can affect the transaction price. This information usually causes the buyer's economic loss. If causes that buyer only wants to purchase low-priced product (adverse selection). It leads to the phenomenon about "Bad money drives out good money" [14-15].

In the stock market, the phenomenon of information asymmetry is even more serious. For their own benefit, large shareholders and high-level managers in companies will buy (sell) stocks in advance and release news that is beneficial (not conducive) to the company afterwards. Increasing (decreasing) the stock price to gain self-interest, this kind of insider trading behavior often occurs. the corporate supervision system is mainly to prevent this behavior and the fundamental reason for the existence of the corporate supervision system is also the persistent information asymmetry in the society.

In the stock market, information asymmetry causes "peacock behavior". Companies like peacocks and enterprise will take effort to generate good data in financial statements in order to let listed companies to sell company products to their subsidiaries. The quarterly profitable financial statements make market retail investors and fund managers mistakenly believe that the company's profit growth is profitable after the stock price rises. This is also the supervision focus of the corporate supervision system [16].

\subsection{Game Theory Research}

The relevant research on the use of game technology for corporate analysis is as follows:

In [17], author used game theory to analyze the financial decision-making of corporate capital. The research results show that the establishment and implementation of corporate governance by the government can reduce incentives for entrepreneurs and accountants to collude and reduce corporate speculation risks. In [18], author used static game model of multinational corporation's parent and subsidiary companies to analyzes the repeat game process of the parent-subsidiary structure of multinational corporations. The research results show that the comprehensive governance of multinational corporations' subsidiaries can help to achieve the goal of "win-win" between the parent company and its subsidiaries. It solves the corporate governance issues of the subsidiaries of multinational companies. In [19], author collected literatures about applying game theory for handling individual and organizational decision-making problem. In [20], author constructed the " Multi- agent game model for governments, consumers and enterprises" in order to analyze which factors can effectively affect the development of green economy by enterprises. The research results show that consumers have a positive attitude towards "green products" and "pseudogreen products". In order to avoid inverse selection behavior, government must conduct subsidy language certification for green products in order to increase the willingness of enterprises to develop green products.

In [21], author uses game theory as a research tool to explore the price of multinational companies and competitors under the four dimensions. The dimensions include "cost structure", "market price", "channel management" and "government's exchange rate policy trend". This model can execute strategy Analysis to select the most suitable price strategy for multinational companies under the condition of exchange rate uncertainty. In [22], author employed Entropy method and analytic network process (ANP) to acquire subjective and objective weight of criteria. Game theory and decision-making trial and evaluation laboratory (DEMATEL) were adopted to adjust weight among subjective criteria and objective criteria and made the analysis result reasonable in supplier selection problem. In [23], author established innovative game model by applying asymmetric normal Z-value (ANZ) to collect relative information. In this model, concordance/discordance index and outranking relation of strategies for different players under multiple criteria were provided according to classic outranking rules. In [24], author handled noncooperative multi-criteria Nash game by using fuzzy robust weighted method (FRWM). In this game, every decision maker can possess his/her several competing objectives. The uncertainty of performance will be evaluated by FRWM. Every player should minimize his/her maximum weighted sum objectives. Fuzzy robust weighted Nash equilibrium (FRWNE) 
will be designed for acquiring weight of each objective. FRWNE can be transferred as mathematical programming problem which can be solved by software. In [25], author used utility function and integrated non-cooperative game and social identity model to evaluate performance of each strategy for self-interested players.

\section{Game Theory Model}

\subsection{Notation Discussion}

Players, Players' Strategies, and Players' Strategies Payoffs are the three basic components of the game. Relative notation is explained as follows:

(1) Players

A group of players can form as player set $\mathrm{p}=\left\{p_{1}, p_{2}, \ldots, p_{v}\right\}, \mathrm{v}$ means the volume of player.

(2) Players' Strategies

Every player has his/her strategies. $s^{1}=$ $\left\{s_{1}^{1}, s_{2}^{1}, \ldots, s_{m_{1}}^{1}\right\}, s^{2}=\left\{s_{1}^{2}, s_{2}^{2}, \ldots, s_{m_{2}}^{2}\right\}, \ldots, s^{v}=\left\{s_{1}^{v}, s_{2}^{v}, \ldots, s_{m_{v}}^{v}\right\}$. $s^{1}, s^{2}, \ldots, s^{v}$ are strategies for player 1 to player $\mathrm{v}$. Where $s_{j}^{i}$ is $\mathrm{j}$-th strategy for player i. $m_{k}$ is the volume of strategy for player $\mathrm{k}$.

(3) Players' Strategies Payoffs

Each player's strategy can combine as the strategy combinations $\left[s_{x_{1}}^{1}, s_{x_{2}}^{2}, \ldots, s_{x_{v}}^{v}\right] . R_{a,\left[s_{x_{1}}, s_{x_{2}}^{2}, \ldots, s_{x_{v}}^{v}\right]}$ is the profit of player a under strategy combination $\left[s_{x_{1}}^{1}, s_{x_{2}}^{2}, \ldots, s_{x_{v}}^{v}\right]$

(4) Selection Probability of Players' Strategies

Single strategy of each player has a certain probability to be selected to be executed by player. $\tau^{1}=\left\{\tau_{1}^{1}, \tau_{2}^{1}, \ldots, \tau_{m_{1}}^{1}\right\}, \tau^{2}=$ $\left\{\tau_{1}^{2}, \tau_{2}^{2}, \ldots, \tau_{m_{2}}^{2}\right\}, \ldots, \tau^{v}=\left\{\tau_{1}^{v}, \tau_{2}^{v}, \ldots, \tau_{m_{v}}^{v}\right\} . \tau_{j}^{i}$ is the probability about i-th player select j-th strategy to execute.

\subsection{Evaluation Model}

There are various general types of games, which can be divided into (1) cooperative games and non-cooperative games, (2) static games and dynamic games, (3) complete information games and incomplete information games. Those game models are explained below [26].

\section{(1) Cooperative and non-cooperative games}

"Non-cooperative game" refers to whether there is a binding agreement between the parties interacting with each other. On the contrary, it is a "cooperative game". Cooperative games will produce collusion. The case in this study is a non-cooperative game.

(2) Static and dynamic games

"Static game" means that the participating players choose strategies at the same time in the game. "Dynamic game" means that the actions of the participating players have a sequence in the game and players who act later can observe the first action chosen by the action player. The case of this study is a static game.

(3) Complete information game and incomplete information game

"Complete information game" means that each participating player has accurate information about the characteristics, strategy space, and profit function of other participating players during the game. Conversely, it is "Incomplete information game" when the participating players cannot grasp complete information. The case of this study is a complete information game.

The complete information non-cooperative static game can be obtained using the following formula:

$\max \quad v^{1}$

Subject to

$$
\begin{aligned}
& \sum_{i=1}^{m_{1}} R_{1,\left[\mathrm{~s}_{\mathrm{i}}^{1}, \mathrm{~s}_{1}^{2}, \mathrm{~s}_{1}^{3}\right]} * \tau_{i}^{1} \geq v^{1} \\
& \sum_{i=1}^{m_{1}} R_{1,\left[\mathrm{~s}_{\mathrm{i}}^{1}, \mathrm{~s}_{1}^{2}, \mathrm{~s}_{2}^{3}\right]}{ }^{*} \tau_{i}^{1} \geq v^{1} \\
& \text {... } \\
& \sum_{i=1}^{m_{1}} R_{1,\left[s_{m_{1}}^{1}, s_{m_{2}}^{2}, s_{m_{3}}^{3}\right]} * \tau_{i}^{1} \geq v^{1}
\end{aligned}
$$

$\max \quad v^{2}$

Subject to $\quad \sum_{i=1}^{m_{2}} R_{2,\left[\mathrm{~s}_{1}^{1}, \mathrm{~s}_{i}^{2}, \mathrm{~s}_{1}^{3}\right]}{ }^{*} \tau_{i}^{2} \geq v^{2}$

$\sum_{i=1}^{m_{2}} R_{2,\left[\mathrm{~s}_{1}^{1}, \mathrm{~s}_{i}^{2}, \mathrm{~s}_{2}^{3}\right]}{ }^{*} \tau_{i}^{2} \geq v^{2}$

$\cdots$

$\sum_{i=1}^{m_{2}} R_{2,\left[\mathrm{~s}_{m_{1}}^{1}, \mathrm{~s}_{m_{2}}^{2}, \mathrm{~s}_{m_{3}}^{3}\right]} \tau_{i}^{2} \geq v^{2}$

$\sum_{i=1}^{m_{2}} \tau_{i}^{2}=1$

$\tau_{i}^{2}>=0 \mathrm{i}=1,2, \ldots, m_{2}$

$\max \quad v^{3}$

Subject to

$$
\begin{aligned}
& \sum_{i=1}^{m_{3}} R_{3,\left[\mathrm{~s}_{1}^{1}, \mathrm{~s}_{i}^{2}, \mathrm{~s}_{1}^{3}\right]} * \tau_{i}^{3} \geq v^{3} \\
& \sum_{i=1}^{m_{3}} R_{3,\left[\mathrm{~s}_{1}^{1}, \mathrm{~s}_{i}^{2}, \mathrm{~s}_{2}^{3}\right]} * \tau_{i}^{3} \geq v^{3} \\
& \text {... } \\
& \sum_{i=1}^{m_{3}} R_{3,\left[\mathrm{~s}_{m_{1}}^{1}, \mathrm{~s}_{m_{2}}^{2}, \mathrm{~s}_{m_{3}}^{3}\right]} \tau_{i}^{3} \geq v^{3} \\
& \sum_{i=1}^{m_{3}} \tau_{i}^{3}=1 \\
& \tau_{i}^{3}>=0 \mathrm{i}=1,2, \ldots, m_{3}
\end{aligned}
$$

\section{Case Study}

\subsection{Case Introduction}

This research uses Tatung as a case study. First, this research explains the current situation of Tatung. Tatung Company is a comprehensive enterprise with the electronics industry as its core technology business. It was founded in 1918. Tatung Company is the first batch of listed companies in Taiwan in the fields of electrical appliance manufacturing, distribution, trade, and construction. It is divided into three major business groups - power, systems, and consumption.

Tatung's main business has performed poorly in recent years. However, its Tatung enterprises have a lot of high-value land. It 
led to marketers wanting to come in and fight for dominance in Tatung company. This is the current situation of Tatung company.

\subsection{Case Analysis}

In this case, it is a three-player game. The players are Tatung company faction $\left(p_{1}\right)$, Tatung market faction $\left(p_{2}\right)$ and Government Supervisor $\left(p_{3}\right)$. The related strategies are summarized in Table 1:

Table 1: The strategies for each player

\begin{tabular}{|l|l|}
\hline \multicolumn{1}{|c|}{ Player } & \multicolumn{1}{c|}{ Strategy of each player } \\
\hline $\begin{array}{l}\text { Tatung company } \\
\text { faction }\end{array}$ & Strategy (1) Find an external merge object (White \\
$p_{1}$ & Horse Knight) $s_{1}^{1}$ \\
& Strategy (2) Swallowing poison pills $s_{2}^{1}$ \\
& Strategy (3) Mass acquisition of equity $s_{3}^{1}$ \\
& Strategy (4) Sued Tatung Market for illegal Chinese \\
investments $s_{4}^{1}$
\end{tabular}

Tatung company faction has 4 strategies, Tatung market faction has 2 strategies, and Government Supervisor have 2 strategies. The total of strategy combinations is $4 * 2 * 2=16$.

In this study, 10 experts were invited to evaluate the effectiveness of the above strategies on the Tatung company faction $\left(p_{1}\right)$, Tatung market faction $\left(p_{2}\right)$ and Government Supervisor $\left(p_{3}\right)$ by using 1 to 10 points ( 1 for the lowest benefit and 10 for the highest benefit) based on the above strategy combination. Experts express their opinion about the effectiveness of each strategy for Tatung company faction $\left(p_{1}\right)$, Tatung market faction $\left(p_{2}\right)$ and Government Supervisor $\left(p_{3}\right)$ under special of strategy combination by taking a value from 1 to 10. All of experts' opinion (evaluation value) will be add to represent the performance of each strategy. The evaluation results can refer to Table 2 to Table 4.

Table 2: The benefits of Tatung company faction under different strategic combinations

\begin{tabular}{|c|c|c|c|c|c|}
\hline & & $s_{1}^{1}$ & $s_{2}^{1}$ & $s_{3}^{1}$ & $s_{4}^{1}$ \\
\hline \multirow{3}{*}{$s_{1}^{3}$} & $s_{1}^{2}$ & 32 & 31 & 23 & 41 \\
\cline { 2 - 6 } & $s_{2}^{2}$ & 27 & 34 & 25 & 28 \\
\hline \multirow{2}{*}{$s_{2}^{3}$} & $s_{1}^{2}$ & 74 & 71 & 63 & 63 \\
\cline { 2 - 6 } & $s_{2}^{2}$ & 84 & 83 & 76 & 72 \\
\hline
\end{tabular}

Table 3: The benefits of Tatung market faction under different strategy combinations

\begin{tabular}{|c|c|c|c|c|c|}
\hline & & $s_{1}^{1}$ & $s_{2}^{1}$ & $s_{3}^{1}$ & $s_{4}^{1}$ \\
\hline \multirow{2}{*}{$s_{1}^{3}$} & $s_{1}^{2}$ & 44 & 34 & 43 & 32 \\
\cline { 2 - 6 } & $s_{2}^{2}$ & 47 & 29 & 41 & 53 \\
\hline \multirow{2}{*}{$s_{2}^{3}$} & $s_{1}^{2}$ & 64 & 52 & 56 & 71 \\
\cline { 2 - 6 } & $s_{2}^{2}$ & 61 & 47 & 52 & 60 \\
\hline
\end{tabular}

Table 4: Benefits of government supervisor units under different strategic combinations

\begin{tabular}{|c|c|c|c|c|c|}
\hline & & $s_{1}^{1}$ & $s_{2}^{1}$ & $s_{3}^{1}$ & $s_{4}^{1}$ \\
\hline \multirow{3}{*}{$s_{1}^{3}$} & $s_{1}^{2}$ & 58 & 64 & 62 & 71 \\
\cline { 2 - 6 } & $s_{2}^{2}$ & 54 & 58 & 60 & 73 \\
\hline \multirow{2}{*}{$s_{2}^{3}$} & $s_{1}^{2}$ & 34 & 27 & 42 & 29 \\
\cline { 2 - 6 } & $s_{2}^{2}$ & 29 & 24 & 37 & 23 \\
\hline
\end{tabular}

The relative formula can refer as follows

$\begin{array}{ll}\max & v^{1} \\ \text { Subject } & 32^{*} \tau_{1}^{1}+31^{*} \tau_{2}^{1}+23^{*} \tau_{3}^{1} \\ \text { to } & 27^{*} \tau_{1}^{1}+34^{*} \tau_{2}^{1}+25^{*} \tau_{3}^{1} \\ & 74^{*} \tau_{1}^{1}+71^{*} \tau_{2}^{1}+63^{*} \tau_{3}^{1}+ \\ & 84^{*} \tau_{1}^{1}+83^{*} \tau_{2}^{1}+76^{*} \tau_{3}^{1} \\ & \sum_{i=1}^{4} \tau_{i}^{1}=1 \\ & \tau_{i}^{1}>=0 \mathrm{i}=1,2, \ldots, 4 \\ \max & v^{2} \\ \text { Subject } & 44^{*} \tau_{1}^{2}+47^{*} \tau_{2}^{2} \geq v^{2} \\ \text { to } & 34^{*} \tau_{1}^{2}+29^{*} \tau_{2}^{2} \geq v^{2} \\ & 43^{*} \tau_{1}^{2}+41^{*} \tau_{2}^{2} \geq v^{2} \\ & 32^{*} \tau_{1}^{2}+53^{*} \tau_{2}^{2} \geq v^{2} \\ & 64^{*} \tau_{1}^{2}+61 * \tau_{2}^{2} \geq v^{2} \\ & 52^{*} \tau_{1}^{2}+47^{*} \tau_{2}^{2} \geq v^{2} \\ & 56^{*} \tau_{1}^{2}+52^{*} \tau_{2}^{2} \geq v^{2} \\ & 71^{*} \tau_{1}^{2}+60^{*} \tau_{2}^{2} \geq v^{2} \\ & \sum_{i=1}^{2} \tau_{i}^{2}=1 \\ & \tau_{i}^{2}>=0 \mathrm{i}=1,2\end{array}$

$\max$

Subject $\quad 58 * \tau_{1}^{3}+34 * \tau_{2}^{3} \geq v^{3}$ $v^{3}$

to

$$
\begin{aligned}
& 64^{*} \tau_{1}^{3}+27^{*} \tau_{2}^{3} \geq v^{3} \\
& 62^{*} \tau_{1}^{3}+42^{*} \tau_{2}^{3} \geq v^{3} \\
& 71^{*} \tau_{1}^{3}+29 * \tau_{2}^{3} \geq v^{3} \\
& 54^{*} \tau_{1}^{3}+29 * \tau_{2}^{3} \geq v^{3} \\
& 58^{*} \tau_{1}^{3}+24 * \tau_{2}^{3} \geq v^{3} \\
& 60^{*} \tau_{1}^{3}+37^{*} \tau_{2}^{3} \geq v^{3} \\
& 73^{*} \tau_{1}^{3}+23 * \tau_{2}^{3} \geq v^{3} \\
& \sum_{i=1}^{2} \tau_{i}^{3}=1 \\
& \tau_{i}^{3}>=0 \mathrm{i}=1,2 .
\end{aligned}
$$

According to formula 1 to formula 3 , the strategy selection probability of Tatung company faction $\left(p_{1}\right)$, Tatung market faction $\left(p_{2}\right)$ and government supervisor $\left(p_{3}\right)$ is as follows. Tatung company faction should randomly adopt a mixed strategy of "swallowing poison pills" or "sue Tatung Market Group as illegal Chinese capital". Tatung market faction should randomly adopt a mixed strategy of "massive acquisition of equity" or "convening temporary stock meetings". The best strategy for government supervisor is to "declare full delivery of Tatung stocks".

Table 5: Probability of different players' strategy choices

\begin{tabular}{|c|c|c|c|c|}
\hline & $s_{1}^{1}$ & $s_{2}^{1}$ & $S_{3}^{1}$ & $S_{4}^{1}$ \\
\hline Probability & $0 \%$ & $35.84 \%$ & $0 \%$ & $64.16 \%$ \\
\hline & $s_{1}^{2}$ & $s_{2}^{2}$ & & \\
\hline Probability & $54.18 \%$ & $46.82 \%$ & & \\
\hline & $S_{1}^{3}$ & $s_{2}^{3}$ & & \\
\hline Probability & $100 \%$ & $0 \%$ & & \\
\hline
\end{tabular}

\section{Conclusion and Future Research}

This research uses Tatung companies as the research target. The game analysis tools are used to explore the best strategies of Tatung company faction, Tatung market faction and government supervisor. The research and analysis results show that government supervisor's best strategy is to take action to deliver the shares of Tatung stocks in full while the Tatung company faction and Tatung market faction are suitable to adopt a mixed 
strategy to gain equity. This result shows that government's best plan is doing something. The two parties who compete for the right to operate are better to adopt a mixed strategy.

This study believes that Tatung company faction's best strategy is to perfect its business operations. This behavior can naturally gain the support of the small investor in the market and there is no motivation for investor to fight for management rights. In addition, selling corporate bonds without voting rights are also a good fund-raising tool to assist companies in obtaining operating resources and preventing market usurpation. Crossshareholding by companies is also a good way to preserve operating rights. This study suggests that the government should assist companies with long-term business failures in their industrial upgrading and transformation in peacetime. It can be known that company may do some damage to shareholders if there is the competition for management rights according to the analysis results of this research. The behavior should be severely punished by taking drastic measures for the efficiency of government supervision. The contribution of this research is to design the framework which can be used to evaluate performance of relative enterprise supervision activity. Based on this framework, we can know which strategy is suitable for government and enterprise. This study uses a static game method to analysis. In the future, relevant scholars may consider to use repeating game to analyze this problem because the battle for management rights in Tatung may continue for many years in the real world.

\section{Conflict of Interest}

The authors declare no conflict of interest.

\section{References}

[1] K. S. Lin, C. H. Yueh, "Democratic Transition and the Saving-Investment Correlation: Evidence from Taiwan," Taiwan Economic Review, 38(4), 461500, 2010. doi. 10.6277/ter.2010.384.2.

[2] S. Yu Chi, H. P. Lin, "Causality relationship between tourism, foreign direct investment and economic growth in Taiwan," Asian Journal of Economic Modelling, 6(3), 287-293, 2018. doi. 10.18488/journal.8.2018.63.287.293.

[3] A. K. H. Chang, V. W. Liu, "A Simple Model of Herd Behavior in a Stock Market under Asymmetric Information," Journal of Risk Management, 7(2), 135-164, 2005. doi. 10.30003/JRM.200507.0002.

[4] C. E. Ko, "Reconstruction of the corporate supervision system, supplemented by an information transparency system, the importance of corporate supervision and information transparency-inspiration from the Asian financial crisis," Accounting Research Monthly, 158, 12-13, 1999.

[5] Y. C. Huang, The Study of Domestic Corporate Governance. Master's Thesis of Business Administration in Chung Yuan Christian University, 2002.

[6] H. Z. Zheng, "Thoughts after the PROCOMP INFORMATICS caseStrengthening the internal governance of the enterprise and perfecting the external supervision mechanism," Accounting Research Monthly, 225, 2835, 2004.

[7] M. J. Huang, "Taiwan's corporate governance and financial supervision should be trending after the tyrant storm. Examining loopholes in laws and regulations to eradicate serious diseases," Accounting Research Monthly, (257), 75-91, 2007.

[8] Z. U. O. Wei, "Dynamic Game between Enterprise and Supervision Department in View of Food Safety," Journal of South China Agricultural University, 3, 2009.

[9] L. L. Zhu, T. Yu, T. S. Xia, "Quality supervision game analysis between government and manufacturing enterprise," Soft Science, 27(1), 47-49, 2013.

[10] J. L. Tangen, L. D. Borders, "Applying information processing theory to supervision: An initial exploration. Counselor Education and Supervision," 56(2), 98-111, 2017. doi. 10.1002/ceas. 12065.

[11] Y. Li, D. Wen, X. Sun, "Quality supervision game between government and online shopping platforms," Total Quality Management \& Business $\begin{array}{llll}\text { Excellence, 29(9-10), } 2018 . & \text { 1246-1258, }\end{array}$ 10.1080/14783363.2018.1487617.

[12] M. Sun, "Non-ferrous metal enterprise supervision system and economic management model analysis," China Metal Bulletin, 6, 90-90, 2018.

[13] L. Wang, C. Liu, "Evolutionary game analysis on government supervision and dairy enterprise in the process of product recall in China," International Journal of Information Systems in the Service Sector, 12(1), 44-66, 2020. doi. 10.4018/IJISSS.2020010104.

[14] N. Dierkens, "Information asymmetry and equity issues," Journal of financial and quantitative analysis, 181-199, 1991. doi. 10.2307/2331264.

[15] D. D. Bergh, D. J. Ketchen Jr, I. Orlandi, P. P. Heugens, B. K. Boyd, "Information asymmetry in management research: Past accomplishments and future opportunities," Journal of management, 45(1), 122-158, 2019. doi. $10.1177 / 0149206318798026$.

[16] G. S. Dawson, R. T. Watson, M. C. "Boudreau, Information asymmetry in information systems consulting: toward a theory of relationship constraints," Journal of Management Information Systems, 27(3), 143-178, 2010. doi: 10.2753/MIS0742-1222270306.

[17] M. C. Wang, S. T. Chiu, "Use Game Theory to Analyze the Auditing Function of Auditors in Corporate Governance," Soochow Journal of economics and business. 68, 39-60, 2010. doi: 10.29735/SJEB.201003.0002.

[18] C. G. Li, S. K. Zhou, "Theoretical analysis of the game of multinational corporate governance structure," Lingdong Journal, 30, 155-181, 2011.

[19] E. K. Zavadskas, Z. Turskis, "Multiple criteria decision making (MCDM) methods in economics: an overview," Technological and economic development of economy, 17(2), 397-427, 2011. doi: 10.3846/20294913.2011.593291.

[20] C. G. Li, Z. Y. Huang, L. L. Wang, "Theoretical analysis of the game between government, enterprise and consumer under the green economy," Lingdong Journal, 33, 49-71, 2013.

[21] C. H. Shyu, Hedging, Pricing and Competition Strategies for Multinational Corporations under Exchange Rate Risk: From the Perspective of Game Theory. Master's Thesis of International Business Management Group in National Taiwan University, 2015.

[22] T. Liu, Y. Deng, F. Chan, "Evidential supplier selection based on DEMATEL and game theory," International Journal of Fuzzy Systems, 20(4), 1321-1333, 2018. doi: 10.1007/s40815-017-0400-4.

[23] H. G. Peng, X. K. Wang, T. L. Wang, J. Q. Wang, "Multi-criteria game model based on the pairwise comparisons of strategies with Z-numbers," Applied Soft Computing, 74, 451-465, 2019. doi: 10.1016/j.asoc.2018.10.026.

[24] Y. Ji, S. Qu, Z. Wu, Z. Liu, “A Fuzzy Robust Weighted Approach for MultiCriteria Bilevel Games," IEEE Transactions on Industrial Informatics, 16(8), 5369-5376, 2020. doi: 10.1109/TII.2020.2969456.

[25] Y. Wang, Z. Bu, H. Yang, H. J. Li, J. Cao, "An effective and scalable overlapping community detection approach: Integrating social identity model and game theory," Applied Mathematics and Computation, 390, 125601, 2021. doi: 10.1016/j.amc.2020.125601.

[26] C. S. Lin, C. T. Chen, F. S. Chen, W. Z. Hung, "A novel multiperson game approach for linguistic multicriteria decision making problems," Mathematical Problems in Engineering, 2014. doi: 10.1155/2014/592326. 